\title{
Hiv/Aids: Knowledge and Practices among the Elderly in Delta State of Nigeria
}

\author{
Dr. Paul Oghenero Okumagba \\ Department of Sociology and Psychology Delta State University, Abraka, Delta State, Nigeria
}

\begin{abstract}
This study is aimed at examining the level of awareness of HIVIAIDS phenomenon among the elderly in selected rural communities of Delta State and how the knowledge acquired is put into practice. A sample of 150 elderly aged 60 years and above was selected from five rural communities using the random sampling technique. The instrument for gathering data was a validated interview schedule reflecting knowledge about means of transmission and prevention of HIV/AIDS and practices of high risk behaviour. The procedure used trained research assistant from the area to administer the research instrument in their native language. The study was carried out between October and December, 2010. One hundred and forty three of the one hundred and fifty elderly studied (95.33\%) knew the sexual route of HIV/AIDS transmission. 68 of the elderly studied (76.6\%) knew the preventive role of condoms, and 111 of the elderly studied (74.0\%) knew the preventive role of restricting ones self to regular sexual partner. A relationship was found between knowledge and practices of preventive measures. There is awareness of the existence of HIV/AIDS, its mode of transmission and the method of prevention. There is however, the problem of changing individual sexual behaviour. However, with the high rate of spread of HIV/AIDS sweeping across the country, health education programmes need to be evaluated for successful implementation of right sexual behaviour in the population.
\end{abstract}

Keywords: Hiv/Aids, Knowledge, Elderly, Practices, Nigeria.

\section{Introduction}

Inspite of the seriousness of the HIV/AIDS pandemic not much empirical work has been done in the area of knowledge and practice particularly among the elderly in Delta State South-South of the Nigerian State. HIV/AIDS problem has become man's major health dilemma with far reaching implications for individual, communities and country at large.

The prevalence of HIV/AIDS among old people is an under - researched topic. The focus is more on the youths. Studies of the elderly pose more challenges as it entails differentiating symptoms of HIV/AIDS compared with those of the normal ageing process (Kassu, et al, 2004[1]). As young people in effected with HIV/AIDS get older, this problem graduates to become a problem associated with the elderly. This is translated into an increasing number of infected people living with HIV/AIDS in the age group 45 years and above. This may be attributed to increase in lifespan due to advancement in HIV/AIDS therapy. Conversely, the perception that people within age bracket perception that people within age bracket 50 years and above are sexually inactive, could mean that they are not targeted for screening or do not expose themselves to the screening process. In such cases, where the elderly are not regularly tested for HIV, the definite data is difficult to obtain and utilized (Anderson (ed) 2010[2]).

In the past two and half decades HIV/AIDS pandemic have become one of the major health challenges in sub-Saharan Africa. This health problem poses great challenges to both researchers and policy makers at various levels. Empirical Data in Nigeria show that in 1990 about half a million persons were infected with HIV/AIDS. This is bound to increase if the spread is left unchecked (Nation AIDS and STD control programme, 2002[3]). The 2009 Sub-Saharan Africa HIV/AIDS status show that Nigeria had 220,000 AIDS deaths and 2,500,000 orphans due to AIDS.

Figures from the joint United Nations programme on HIV/AIDS (UNAIDS) in 2009 revealed that more than 33.3 million people were living with HIV, this figure being largely proportional to sub-Saharan Africa of which $70 \%$ were African. Further more, 2.6 million people had been infected with HIV, while an estimated 1.8 million people died of AIDS. Of the 33 where the HIV/AIDS rate has fallen beyond 25\%, 22 of those countries are located in sub-Saharan Africa.

Surprisingly, half of the people living with HIVS are in fact woman and girl (UNAIDS, 2010[]). What is striking is the way it unfolds, spreading from individual to families and from there into communities. The effect of this on the elderly is extreme, as it is they who have to carry the financial and physical burden of caring for surviving 'AIDS orphans'. HIV/AIDS is often transferred to the elderly through secondary infection, which occurs through normal daily activities within the context of the poverty-stricken society, where there is great deal of intimacy (Mba, 2007[5]). 
The first two cases of HIV/AIDS in Nigeria were reported at an international AIDS conference in 1986. The response of the Nigerian state was slow initially and it was only in 1991 that the Nigerian state made the first attempt at assessing Nigerian's HIV/AIDS situation. The result of this assessment show that about 1.8 percent of the Nigerian population were infected with HIV/AIDS (UNAIDS 2008[6]). Further surveillance report show that HIV/AIDS prevalence rose from 3.8 percent in 1993 to 4.5 percent in 1998. This shows 7 percent increase of the pandemic within a period of six years.

Hosegood and Timaeus (2005[7]) identified several ways in which the elderly experience ways in which the elderly experience the impact of HIV/AIDS pandemic in their families or at the level of house holds. These includes; care-giving, co-residence will ill adults, of the need of give financial or material support, paying for financial of diseased child, fostering grandchildren and dealing with negative community reactions. Drimie (2003[8]) confirmed that given the increase of new infection cases of HIV/AIDS, this pandemic will seriously have impact on range of land and livelihood strategies.

Lothe and Gurung (2008[9]) observed that a large proportion of peace keeper's knowledge level of HIV/AIDS pandemic was found to be relatively high but with significant variations between contingents. However, some misconceptions were identified, the most common ones include being infected through mosquito bites and sharing meal with an HIV positive patient. The complete knowledge of condom protection, measured by stating three ways of protection was also high. This ranged from 76.1 percent to 97 percent. The most reported sources of obtaining condoms were international missions such as the UN clinic or battalion military clinic, officer's mess or soldiers' canteen, bath rooms and from peer educators. Other sources mentioned outside the mission area were a private store or pharmacy. Sadig, Maligoub and Hussein (2009[10]) in their study of women tea sellers in Khartoum state found the main source of knowledge of HIV/AIDS was radio $(51.2 \%)$, followed by friends and relatives $(47.1 \%)$. The sample studied also had knowledge of symptom of HIV/AIDS. For example, $16.3 \%$ of the respondents knew that continuous diarrhoea is one of the symptom, $23.7 \%$ of the respondents know that loss of weight is also a major symptoms. $72.1 \%$ of those studied knew that HIV could be transmitted through heterosexual contact, $38.1 \%$ through blood transfusion, $3.5 \%$ during pregnancy, $1 \%$ using skin piercing instruments. $55.4 \%$ through placenta, $8.8 \%$ during child delivery and $14.9 \%$ contact through breast feeding. The study also showed that the best known methods for preventing HID/AIDS among those studied were $64.5 \%$ avoiding unprotected sex, $12.1 \%$ keeping to one partner, $47.4 \%$ avoid the use or sharing skin piecing instruments and $3.5 \%$ the use of condoms during heterosexual contacts. The study revealed that the use of condoms by respondents is as a result of knowledge of STD, STD's patients behaviour, the prevalence of HIV/AIDS among the tea setters, History of operations or blood transfusion and knowledge of HIV/AIDS.

USAID(2007[11]), found the level of knowledge of HIV/AIDS to be fair among health care providers in the study hospitals. In all, providers were familiar with the mode of HIV transmission, but had existing gaps in terms of knowledge acquisition relating to HIV virology and infection prevention procedures. More than half of those studied were unaware of the six months period necessary to diagnose HIV and most selected accidentally pricking oneself as a potential pathway for transmission. Few of them knew strategies to decrease the risk of accidental pricks, like not recapping neddles or using the one handed scoop method. Most of the providers studied were also found to be knowledgeable of transmission from mother to child, but selected only blood and semen as bodily fluid that can be responsible for transmitting HIV. The Study also reveals that providers with HIV training had significantly improve such knowledge regarding HIV transmission and prevention. However training may not have been responsible for providing adequate information in these areas, since the knowledge Scores for some items were low for all workers. These results suggest that all health care providers may benefit from increased HIV/AIDS education which recognizes existing gap and misconceptions and covers how to reduce occupational risks and prevent infection.

In China, the knowledge of HIV and negative attitude among nurses were inversely correlated; $50 \%$ of the nurses reported anxiety about becoming infected with HIV in their places of work, and $49 \%$ opined that they avoided Contact with Persons living with HIV/AIDS (Chen, Han and Holzemer 2004[12]). USAID, (2007[11]), also found out that the knowledge of HIV/AIDS is associated with Stigma. This has been shown in other Studies, where receipt of training was often used as proxy for overall knowledge of the pandemic. (Knussen and Niven, 1999[13]; Chen, Han and Holzemer, 2004[12]; Quach et al. 2005[14]; Hamra et el. 2006[15]; Kermode et el. 2005[16]; Ijeduola et el. 2007[17])

Udjo (2006[18]), posits that demographic transition from the high fertility and mortality to low fertility and mortality is set within the structure of graduation from a young to an ageing population. Moreover, given the increased number of the elderly in South Africa and considering the increase of this category of population, the employer has to plan for an increase in the magnitude of pension payment.

However, the older people are not considered at risk but they are. Given, the advancement in pharmaceutical products and introduction, to the market of Viagra, this has contributed to an increase in sexual intercourse among the elderly population, who consider the use of contraception or STDs barriers unnecessary as they have passed their child bearing age (Anderson, (ed) 2010[2]). 
Shell and Zeitlin, (2000[19]) posits that young girls are also targeted by older men who are infected with HIV/AIDS. These have the believe that having sexual contract with a virgin will help in curing them of the disease and ensnare young girls from poverty stricken backgrounds with the promise of financial security.

Moreover there is another side of the 'sugar daddy' phenomenon which is also a significant factor in the spread of HIV/AIDS. There is a transaction sex relationship where the girls look for the old men. The relationship is characterized by transaction of money or gifts. Unfortunately they are exposing themselves to older people who have had many sexual partners previously and are HIV/AIDS positive. (Gbala jobi, 1999[20]).

\section{Methods}

The Cross - Sectional Survey research method was used to collect the data for the Study. The data were obtained between October and December, 2010. A total of 150 elderly aged 60 years and above were randomly selected from six selected Communities in Delta State of Nigeria. The multi- stage random Sampling method was used to sample the respondents from the three senatorial district of Delta State of Nigeria.

A Three stage sampling technique was adopted to the Sample Studied. The first stage involved the Clustering of the twenty five (25) Local Government Areas into three Strata using the existing Senatorial districts (i.e. Delta North, Delta South and Delta Central). Two Local Government Areas were randomly sampled from each of the Three Senatorial districts. In the Second Stage, two rural communities were randomly sampled from each of the two Local Government Areas earlier selected for the study. The third and final stage of sampling process involved the selection of respondents from the six rural Communities for the Study. The final Stage involved random Sampling of household in the Communities from which the final Samples for the Study were selected.

A validated interview Schedule reflecting knowledge about how HIV/AIDS and the profile of high risk behaviour was designed to elicit information from the Sample. The data for the study were collected by trained field assistants who used local languages and pigeon English. This however, took a longer time to administer given the age of persons in the Study Sample. The SPSS/PC+ Computer Software Package (Version 10.0) was used to analyse the data.

Table I. Showing Local Government Areas and Communities in the Study Sample.

\begin{tabular}{|l|l|l|}
\hline Senatorial District & $\begin{array}{l}\text { Local Government Areas ( } \\
\text { LGA's) }\end{array}$ & $\begin{array}{l}\text { Communities } \\
\text { Ika South } \\
\text { Ukwani }\end{array}$ \\
\hline Central & $\begin{array}{l}\text { Ethiope East } \\
\text { Ughelli North }\end{array}$ & $\begin{array}{l}\text { Abavo } \\
\text { Umuebu }\end{array}$ \\
\hline South & $\begin{array}{l}\text { Isoko South } \\
\text { Warri South }\end{array}$ & $\begin{array}{l}\text { Oria - Abraka } \\
\text { Aragba - Orogun }\end{array}$ \\
\hline
\end{tabular}

The analysis of the empirical data generated from the respondents is divided into three sub-sections namely: Socio- economics Characteristics of the respondents about HIV/AIDS Pandemic and Practice (i.e. Prevention of HIV/AIDS). In addition, a hypothesis was tested on the relationship between Knowledge and Practices of HIV/AIDS Prevention..

Table 2. Socio- economics Characteristics of Sample Studied.

\begin{tabular}{|l|l|l|}
\hline Variable & No. of Sample & \% of Sample \\
\hline Age of Sample & & \\
\hline 60- 65 & 53 & 35.30 \\
\hline 66- 70 & 69 & 46.00 \\
\hline $\mathbf{7 0}$ and above & 28 & 18.70 \\
\hline Total & $\mathbf{1 5 0}$ & $\mathbf{1 0 0 . 0 0 \%}$ \\
\hline Sex of Sample & & \\
\hline Male & 97 & 64.67 \\
\hline Female & 53 & 35.33 \\
\hline Total & $\mathbf{1 5 0}$ & $\mathbf{1 0 0 . 0 0 \%}$ \\
\hline Level of Education & & \\
\hline University & 31 & 20.37 \\
\hline NCE/Polytechnic & 26 & 17.33 \\
\hline Secondary & 38 & 25.33 \\
\hline Primary & 25 & 16.67 \\
\hline No Education & 30 & 20.00 \\
\hline
\end{tabular}


Hiv/Aids: Knowledge And Practices Among The Elderly In Delta State Of Nigeria

\begin{tabular}{|l|l|l|}
\hline Total & $\mathbf{1 5 0}$ & $\mathbf{1 0 0 . 0 0 \%}$ \\
\hline Religion of Sample & & \\
\hline Christianity & 103 & 68.67 \\
\hline Islam & 8 & 5.33 \\
\hline $\begin{array}{l}\text { African } \\
\text { Traditional } \\
\text { Religion }\end{array}$ & 39 & 26 \\
\hline Total & $\mathbf{1 5 0}$ & $\mathbf{1 0 0 . 0 0 \%}$ \\
\hline Monthly Income & & \\
\hline Under N7,500 & 21 & 14.00 \\
\hline N7,500- N15,000 & 38 & 25.00 \\
\hline N15,000- N30,000 & 36 & 24.00 \\
\hline N31,000- N65,000 & 20 & 13.33 \\
\hline Above N65,000 & 20 & 23.34 \\
\hline Total & $\mathbf{1 5 0}$ & $\mathbf{1 0 0 . 0 0 \%}$ \\
\hline $\begin{array}{l}\text { Primary } \\
\text { Occupation }\end{array}$ & & \\
\hline Farming & 28 & 18.67 \\
\hline Petty Trading & 37 & 24.67 \\
\hline Artisan & 24 & 16.00 \\
\hline Not engaged & 61 & 40.66 \\
\hline Total & $\mathbf{1 5 0}$ & $\mathbf{1 0 0 . 0 0 \%}$ \\
\hline Family Size & & 26.00 \\
\hline Under 6 & 39 & 28.00 \\
\hline 7- 12 & 42 & 46.00 \\
\hline $\mathbf{1 3}$ and above & 69 & $\mathbf{1 0 0 . 0 0 \%}$ \\
\hline Total & $\mathbf{1 5 0}$ & 62.00 \\
\hline Marital Status & & 15.30 \\
\hline Married & 93 & 22.70 \\
\hline Separated & 23 & $\mathbf{1 0 0 . 0 0 \%}$ \\
\hline Widow ed & 34 & \\
\hline Total & $\mathbf{1 5 0}$ & \\
\hline & & \\
\hline
\end{tabular}

\section{(a) Socio - economic background of the elderly Studied}

Table 2 shows the Socio - economic Characteristics of the Sample Studied.

The data on age shows that majority of the Sample (46 percent) of the Sample Studied fall within the age bracket $66-70$ years. This is followed by those who fall within age bracket $60-65$ years (35.30 percent) and those who are 70 years and above are 18.70 percent of the total Sample

The table shows that 64.67 percent of the samples were Male while 35.33 percent were female. The table shows that 25.33 percent of the respondents had Secondary School education. This is followed by University education and NCE and Polytechnic with 20.67 and 17.33 percent respectively. Those with Primary education were 16.67 percent while those with no education were 20.00 percent of the total Sample Studied. These shows that a large proportion of the elderly studied are between Monthly income of $\mathrm{N} 7,500-\mathrm{N} 15,000$ and N 15,000 - N 30,000 respectively. The Monthly income of N 65,000 and above is represented by 23.34 percent, while those under monthly income of N 7,500 represent 14.00 percent. Those on Monthly income of N31, 000 - N 65,000 are 13.33 percent of the Sample Studied. The data on Marital Status of the respondents showed that the majority of them are married (62.0 percent), while 22.7 percent of them are widowed. This is followed by those who are separated respectively 15.3 percent of the Sample Studied. Table 2 which indicates the Socio - economic characteristics of the Sample showed that majority of the elderly are not engaged in any form of occupation (40.66 percent).

This may be due to their age and Health Challenges. This is followed by those engaged in petty trading. (24.67 percent) who are mostly women. The table shows that those engaged in farming and Artisan represent 18.67 and 16.00 percent of the Sample respectively.

The data generated and analysed showed that (46.00percent) majority, of the elderly Studied had large family Size of 13 and above. This is expected given the prevalence of large family sizes in Africa.

The table further shows those with Small family Sizes (i.e under 16) and medium Sized Families (7.12 percent) were 26.00 and 28.00 percent respectively.

The major Religious affiliations of the Sample are Christianity (68.67 percent). This is followed by African Traditional Religion (26.00 percent). The Muslims represent 5.33 percent of the Sample. 
(b) The Elderly Knowledge of HIV/AIDS Pandemic.

Table 3 below shows the data generated and analysed on the Elderly Knowledge of HIV/AIDS and the medium through which the Knowledge is acquired. The table shows that 92.67 percent of the Sample claimed to have heard of the HIV/AIDS Pandemic while 7. 33 percent claimed not to have heard about the Pandemic. The data in table $3^{\mathrm{A}}$ shows that a large proportion of the Sample indicated that they got Knowledge of HIV/AIDS through a Campaign and others which include friends, relatives and medical practitioner. These represents 30.67 percent and 32.67 percent respectively. While 20.00 and 16.66 percent of the Sample received knowledge of the pandemic through Television and Radio respectively.

\section{Ways of Being Infected By HIV/AIDS}

Table 4 shows the various ways of being infected by HIV. This includes, Sex, with 95.33 Percent accepted the fact that people can be infected through Sex, while 4.67 percent of them disagreed. This group of persons are likely to be ignorant of the knowledge and sources of HIV/AIDS.

The Sample also believed that HIV/AIDS Pandemic can be transmitted through blood transfusion. A large proportion of the Sample (82.00 percent) argued that HIV/AIDS can be transferred through blood transfusion. Other ways to be infected with HIV/AIDS is in sharing of Sharp Objects (65.33 Percent). A large proportion of the Sample do not agree with fact that HIV/AIDS can be contacted by caring for people living with HIV/AIDS ( 96.67 Percent)

Table $3^{A}$ : Elderly Knowledge of HIV/AIDS Pandemic

\begin{tabular}{|l|l|l|}
\hline $\begin{array}{l}\text { Variables } \\
\text { Have you ever Heard of HIV/AIDS? }\end{array}$ & Frequency & Percentage (\%) \\
\hline Yes & 139 & 92.67 \\
\hline No & 11 & 7.33 \\
\hline Total & $\mathbf{1 5 0}$ & $\mathbf{1 0 0 . 0 0 \%}$ \\
\hline
\end{tabular}

Table $3^{\mathrm{B}}$ : The Elderly Medium of Knowledge of HIV/AIDS

\begin{tabular}{|l|l|l|}
\hline Television & 30 & 20.00 \\
\hline Radio & 25 & 16.66 \\
\hline Campaign & 46 & 30.67 \\
\hline Others & 49 & 32.67 \\
\hline Total & $\mathbf{1 5 0}$ & $\mathbf{1 0 0 . 0 0 \%}$ \\
\hline
\end{tabular}

Table 4(a): What ways can one be infected with HIV infection? Through Sex.

\begin{tabular}{|l|l|l|}
\hline Yes & 143 & 95.33 \\
\hline No & 7 & 4.67 \\
\hline Total & $\mathbf{1 5 0}$ & $\mathbf{1 0 0 . 0 0 \%}$ \\
\hline
\end{tabular}

Table $4^{\mathrm{B}}$ Blood transfusion

\begin{tabular}{|l|l|l|}
\hline Yes & 123 & 82.00 \\
\hline No & 27 & 18.00 \\
\hline Total & $\mathbf{1 5 0}$ & $\mathbf{1 0 0 . 0 0 \%}$ \\
\hline
\end{tabular}

Table $4^{\mathrm{C}}$ : Sharing of Sharp Objects

\begin{tabular}{|l|l|l|}
\hline Yes & 98 & 65.33 \\
\hline No & 52 & 34.67 \\
\hline Total & $\mathbf{1 5 0}$ & $\mathbf{1 0 0 . 0 0 \%}$ \\
\hline
\end{tabular}

Table $4^{\mathrm{D}}$ : Providing care for people living with HIV/AIDS

\begin{tabular}{|l|l|l|}
\hline Yes & 5 & $3.33 \%$ \\
\hline No & 145 & 96.67 \\
\hline Total & $\mathbf{1 5 0}$ & $\mathbf{1 0 0 . 0 0 \%}$ \\
\hline
\end{tabular}

The Elderly Practice of Prevention of HIV/AIDS Pandemic

Table 5 below shows the practices of preventing the infection of HIV/AIDS by the elderly Studied. The Sample identified abstinence (90.67 percent) as the major practice of preventing. The Sample also sees the use of Condom (76.67 percent) and the maintenance of a Single Sex partner (74.00 percent) as major practice of preventing HIV/AIDS Pandemic. 
Hiv/Aids: Knowledge And Practices Among The Elderly In Delta State Of Nigeria

Table 5 Elderly Practice of prevention of HIV/AIDS Pandemic

Ways of Preventing Infection of HIV/AIDS

\begin{tabular}{|l|l|l|}
\hline Abstinence & Frequency & Percentage \% \\
\hline Yes & 136 & 90.67 \\
\hline No & 14 & 9.33 \\
\hline Total & $\mathbf{1 5 0}$ & $\mathbf{1 0 0 . 0 0 \%}$ \\
\hline Use of Condom & & \\
\hline Yes & 115 & 76.67 \\
\hline No & 35 & 23.33 \\
\hline Total & $\mathbf{1 5 0}$ & $\mathbf{1 0 0 . 0 0 \%}$ \\
\hline Maintaining one sex Partner & & \\
\hline Yes & 111 & 74.00 \\
\hline No & 39 & 26.00 \\
\hline Total & $\mathbf{1 5 0}$ & $\mathbf{1 0 0 . 0 0 \%}$ \\
\hline
\end{tabular}

Relationship between Knowledge of HIV/AIDS and Practice

The hypothesis is accepted at $\mathrm{P}<0.05$ level of Significance. The decision is traced on the Parsons Chi- Square result of the relationship, which is 47.84 , degree of freedom $=1$ and $\mathrm{P}=0.05$. This means that there is a significant relationship between Knowledge of HIV/AIDS and Practice i.e. taking step to prevent infection by HIV.

Table 5: Relationship between Knowledge and Practice

\begin{tabular}{|l|l|l|l|}
\hline $\begin{array}{l}\text { Variables } \\
\text { Knowledge of HIV/AIDS }\end{array}$ & \multicolumn{4}{|l|}{ Yes } & 25 & $139(92.67 \%)$ \\
\hline Yes & 114 & 8 & $11(7.33 \%)$ \\
\hline No & 3 & $\mathbf{3 3 ( 2 2 . 0 0 \% )}$ & $\mathbf{1 5 0}$ \\
\hline Total & $\mathbf{1 1 7}(\mathbf{7 8 . 0})$ & No & \multicolumn{1}{l|}{ Total } \\
\hline \multicolumn{4}{|l}{$\mathrm{X}^{2}=17.81, \mathrm{df}=1, \mathrm{P}=0.05, \mathrm{C}=3.84$} \\
\hline
\end{tabular}

IV. Conclusion

Findings from the study have provided relevant information about the level of knowledge of HIV/AIDS transmission and prevention. The present study Inspite of limitations, the data are consistent with other studies. The knowledge of HIV/AIDS Pandemic is widespread among the elderly. The study has also shown that there is high level of practice by the elderly. A large number of them were found to be informed in practices aimed at the prevention of HIV/AIDS infection. This can be responsible for the relationship between knowledge and practice of the HIV/AIDS pandemic among the elderly.

There is the need for appropriate and holistic intervention programme to be urgently designed and implemented among the elderly in Nigeria. There is the need to further encourage the use of preventive measures by the elderly in Nigeria. This will further reduce the level of vulnerability of the elderly to the HIV/AIDS epidemic in Nigeria.

\section{References}

[1]. Kassu A, Mekonnem A, Bekele A, Abseno N, Melese E, Moges F, Wondmikun Y, and Ota F, HIV and Syphilis infection among elderly people on Northwest Ethiope, Japan Journal of Health Sciences 14, (2004). 201 - 211

12]. Anderson M, (ed) . Hiv/aids and the elderly, http://www.finalcall.com/artman/publish/article_2010.shtml National AIDS and STD Control HIV/AIDS in Nigeria: Overview of the Epidemic. Federal Ministry of Health. (2002) UNAIDS, Unaids report on the global aids epidemic 2010, Tech. Report 364 UNAIDS, Unaids report on the global aids epidemic 2008, Tech. Report.

[6]. Mba C.J. Impact of HIV/AIDS mortality on South Africa's life expectancy and implications for the elderly population, African Journal of Health Sciences 14, 2007.201-211.

[7]. Hosegood V, and Timaeus I.M. The impact of adult mortality on the living arrangements of older people in rural South Africa, Cambridge University Press 25, 2005.431-444.

[8]. Drimie S. HID/AIDS and land: cases studies from Kenya, lesotho and South Africa, Development Southern Africa 20:5, 2. 2003

[9]. Lothe, E. and Gurung, M.:HIV/AIDS Knowledge, Attitude and Practice survey: UN Uniformed Peacekeepers in Haiti. 2007

[10]. Sidiq Amira MD, Mahgoub Alsadig DTPH and Hussein Abbashar MD. (). A study of knowledge, attitude, practice towards HIV/AIDS and prevalence of HIV/AIDS among tea sellers women in Khartoum State. Sudanese Journal of Public Health. Vol. 4. No.1. 2009

[11]. USAID: Evaluation of Knowledge, attitudes, and Practices of Health care Providers towards HIV - positive patients in Tanzania. 2007

[12]. Chen WT, Han M, and Holzemer WL. Nurses' knowledge, attitudes, and practice related to HIV transmission in north-eastern China. AIDS Patients Care and STDs 18(7): 2004. 417- 22

[13]. Knussen C and Niven C.. HIV/AIDS and health care workers: Contact with patients and attitudes towards them. Psychology and Health 14(3): $1999.367-78$. 
[14]. Quach L, Mayer K, McGarvey ST, Lurie MN, and Phuong D.. Knowledge, attitude and practices among physicians on HIV/AIDS in Quang Ninh, Vietnam. AIDS Patient Care and STDs 19(5): 2005.335-46

[15]. Hamra M, Ross M, Orrs M, and D' Agostino A. Relationship between expressed HIV/AIDS- related stigma and HIV - beliefs/ knowledge and behaviour in families of HIV infected children in Kenya. Tropical Medicine \& International Health 11 (4): 2006.51327

[16]. Kermode M, Holmes W, Langkham B, Thomas M, and Gifford S.. HIV -related knowledge, attitudes and risk perceptions amongst nurses, doctors and other healthcare workers in rural India. Indian Journal of Medical Research 122: 2005.258- 64

[17]. Ijadunola K, Ijadunola M, Abiona T, Odu O, and Akinyemi A. Correlates of physicians' attitudes towards communication with HIV/AIDS patients in Ile - Ife, Nigeria. European Journal of Contraception and Reproductive Health Care 12(1): 2007. 76 - 85.

[18]. Udjo E.O. Demographic impact on HIV/AIDS on the young and elderly population on South Africa, Journal of Intergenerational Relationships 4:2, 2006.1-23

[19]. Shell R.C.H, and Zeitlin R.Positive outcomes: the chance of acquiring HIV AIDS during the school-going years in the Eastern Cape, 1990-2000, The Social work practitioner-researcher 12:3, 2000. 139-154

[20]. Gbalajobi T. Construction sexual identities within 'sugar daddy' relationships: A case study of sexuality constructs among students at the University of the Witwatersrand, Masterthesis, University of the Witwaterand. 1999 